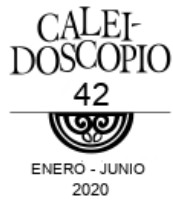

Reseñas

\title{
Reseña de Barrero (2017) La psicología como engaño ¿Adaptar o subvertir?
}

Review of Barrero (2017) La psicología como engaño ¿Adaptar o subvertir?

CRISTINA VILLEGAS RAMÍREZ

Barrero Cuellar, Edgar (2017). La psicología como engaño ¿Adaptar o subvertir?

Bogotá: Ediciones Cátedra Libre.

Edgar Barrero es un psicólogo social que desde una postura crítica se ha interesado en las problemáticas de América Latina. En su libro La psicología como engaño ${ }^{2}$ destaca la forma de pensar y hacer psicología en América Latina, particularmente en el contexto colombiano.

El libro está constituido por cuatro capítulos. En el capítulo uno "Utopías y paradojas de la psicología" el autor aborda el devenir histórico y las problemáticas implícitas en el desarrollo de la psicología desde la perspectiva de la psicología de la liberación. Destaca que la psicología en Colombia ha sido una psicología colonizada e imitativa de

\footnotetext{
${ }^{1}$ psic.cristinavillegas@gmail.com

${ }^{2}$ Existe una edición no venial disponible en http://www.catedralibremartinbaro.org/ pdfs/libro_psicologia_como_engano.pdf
} 
los modelos europeos y norteamericanos de Psicología. La incursión de la disciplina psicológica en el año de 1947 con el primer instituto de psicología, tuvo lugar en un contexto plagado de violencia y atrocidad, sin embargo, la psicología, a diferencia de otras disciplinas pertenecientes a las ciencias sociales y humanidades, le dio la espalda a las problemáticas que aquejaban al país. Esta forma de actuación disciplinar paso a formar parte de la psicología hegemónica en Colombia caracterizada por la sumisión, obediencia y por una colonización intelectual.

La falla estructural de la psicología se refleja en el aislamiento de las complejas realidades sociales, políticas, económicas y culturales. La mayoría de los profesionistas de la psicología en Colombia no se han interesado en los problemas de violencia política, corrupción, impunidad, inseguridad, desigualdad, etc. que son temas prioritarios en el contexto colombiano. La psicología no debería ser partícipe ni pretender neutralidad ante acciones que vayan en contra de la humanidad como la pobreza, violencia, desigualdad, tortura, ocultamiento sistemático de la verdad, manipulación social en torno a intereses económicos, políticos o ideológicos, etc.

La disciplina psicológica tiene un carácter inherentemente político ya sea al colocar el saber psicológico al servicio de intereses políticos a través de la dominación, manipulación y el control social, o bien, al servicio de principios ético-políticos como la emancipación, la autonomía, la descolonización, la libertad, los derechos humanos y la dignidad del ser humano. Es por ello que los principios éticos disciplinares deben reflejarse en la praxis, de lo contrario se pierde la razón de ser de la disciplina dando como resultado una psicología ilegitima que participa en la degradación del ser humano, que guarda silencio ante la violencia, muerte, sufrimiento, discriminación. 
Una crítica a la psicología es la búsqueda constante de explicaciones teóricas de fenómenos políticos sin comprometerse a realizar cambios en la realidad social. La psicología más que ayudar a resolver problemas sociales los ha empeorado pues existe una constante psicologización de los fenómenos individuales y colectivos y una mínima praxis transformadora de los problemas que afectan a las mayorías.

La apuesta ético-política de la psicología latinoamericana implica 1) la ética que legitima la praxis psicológica 2) un cambio en los roles y las posturas ético-políticas con el fin de utilizar el saber psicológico en la transformación de las condiciones de opresión social y 3) la necesidad de revisar las fallas estructurales de la psicología que se reflejan en lo epistémico, lo teórico, lo metodológico y en la praxis.

Uno de los grandes problemas de la psicología es que está al servicio de las minorías poderosas y distante de las mayorías empobrecidas y marginadas por el sistema a través de la producción de conocimientos desde dos dispositivos básicos: la patologización y psicologización de la vida cotidiana.

Posterior al análisis histórico de la psicología en Colombia el autor plantea una serie de paradojas y utopías de la psicología. Respecto a las utopías de la psicología, Fals Borda (2012) sostiene que la utopía se puede entender como "orientaciones que trascienden la realidad cuando, al pasar al plano de la práctica, tiendan a destruir... el orden de cosas existente en una determinada época". La utopía es en sí misma subversiva por su alta dosis libertaria hace que el "ciego vea" y el "mudo hable".

Las tres utopías que plantea el autor para dar lugar a una nueva psicología al servicio del buen vivir en condiciones de igualdad son: 
1. Una Psicología desde abajo y desde adentro al servicio de las grandes mayorías.

2. El compromiso ético-político.

3. Aportes para la construcción de la paz democrática en regiones con una violencia política naturalizada.

Por otra parte, la paradoja es una realidad contradictoria en sí misma tal como la psicología es una realidad contradictoria entre la teoría y la praxis. El discurso psicológico exalta el bienestar de la humanidad pero en la práctica lo niega desde sutiles dispositivos de poder. A continuación se mencionan las cinco paradojas de la psicología:

1. La negación práctica de la propia elaboración discursiva.

2. Una psicología con excesiva elaboración discursiva pero con escasísima investigación para la participación social, política y cultural.

3. Una psicología con una racionalidad crítico discursiva pero con voluntad marginalista y de autocensura.

4. Prácticas de subjetivación no comprometidas con la voluntad de poder-ponerse al servicio de las mayorías excluidas, sino con la evasión de ser actor participante del acontecimiento psicopolítico.

5. Autoexclusión paranoide que nos hace creer que todo lo sabemos y por lo tanto prescindimos de los otros saberes, ya sean científicos o populares.

En el capítulo dos "Lo que NO investiga la psicología en Colombia. El imperio academicista por encima de la realidad histórica", presenta una investigación cuyo objetivo fue realizar una revisión de diez de los principales problemas de Colombia a partir del análisis crítico de la prensa escrita. Una vez establecidas esas diez grandes problemáticas estructurales -violencia política, conflicto armado, narcotráfico, corrupción, impunidad, democracia, 
desigualdad, derechos humanos, paz, inseguridad- procedió a utilizar el análisis crítico del discurso en dos grandes áreas representativas de la psicología en el país: el libro "Historia de la Psicología en Colombia" del profesor Rubén Ardila (2013), y el estado actual de la investigación psicológica en Colombia de los 122 grupos de investigación registrados y acreditados hasta el 2016 en el Sistema Nacional de Ciencia y Tecnología.

Los resultados demuestran que la historia tiene un carácter engañoso pues no corresponde la realidad social, histórica, económica y cultural de Colombia. Existe poca investigación sobre los acontecimientos sociopolíticos propios del contexto colombiano y en cambio se han realizado investigaciones enfocadas en la medición y evaluación con fines adaptativos en diversos escenarios (escuela e industria, principalmente).

Barrero no realizó el análisis de la historia de la piscología con el fin de mostrar lo que se ha hecho sino de señalar críticamente lo que se ha dejado de hacer en estos setenta años de desarrollo de la psicología en Colombia. En el análisis se cristaliza la falta de trabajos de investigación que se relacionen con la realidad del país ya que existe una mínima o nula participación en los problemas estructurales del país.

El principio de negatividad en la psicología mencionado por Martín-Baró (1998) se refería precisamente al problema de lo históricamente negado, a la realidad ignorada. Esa negación de la mirada de problemas que se han presentado a los largo de la historia colombiana se manifiesta hoy en la ceguera epistémica y metodológica, en una psicología incapaz de dar cuenta de complejos procesos de subjetivación atravesados por la guerra, la barbarie, la corrupción, la impunidad, el miedo, la miseria y las torturas psicológicas. 
En el capítulo tres "La praxis ético-política: un asunto pendiente de la psicología con vocación latinoamericanista" Edgar Barrero aborda la incoherencia entre los discursos y prácticas de los psicólogos y de los movimientos de la Psicología en América Latina. Solo algunos movimientos cumplen parcialmente con una praxis ético-política, con una visión crítica centrada en el contexto latinoamericano y un compromiso transformador. En muchas ocasiones el pensamiento psicosocial producido en Latinoamérica es estigmatizado, denigrado y marginado como consecuencia de la condición histórica de sumisión y obediencia ante la psicología europea y norteamericana. De acuerdo con Orlando Fals (2012) esta colonización intelectual una vez instalada es difícil de erradicar. En consecuencia la psicología tiene poca relevancia social en la construcción de políticas para el buen vivir psico-socio-antropológico y es debido al alejamiento de por lo menos siete campos de luchas cotidianas de nuestros pueblos que se mencionan a continuación:

1. Vida digna y buen vivir

2. Territorios libres y auto determinados

3. Pensamiento y espiritualidad descolonizados

4. Palabra autónoma y des enajenad

5. Diversidades efectivas

6. Preponderancia del discurso encantador por encima de la praxis comprometida ética, política y socialmente.

7. Ausencia de investigación psico-socio-antropológica para la integración y la unidad de la Psicología en favor de los menos favorecidos.

En el cuarto capítulo "Formación de psicólogas y psicólogos en América Latina: hacia una nueva razón ético-política para la humanidad" el autor retoma el problema de la formación de psicólogas ya que ha sido a 
través de las universidades que se nos ha colonizado afectiva, cognitiva y espiritualmente para la sumisión frente a los intereses norteamericanos y europeos y al mismo tiempo para el desprecio, desconocimiento e invisibilización del pensamiento psicológico latinoamericanista. La importancia de cambio en la formación de nuevos profesionistas de la psicología es vital ya que ellos son los futuros profesionistas cuya praxis influirá (o no) en la transformación de la realidad social.

Resalta que no se puede ser una psicóloga o un psicólogo latinoamericanista si continuamos reproduciendo las prácticas perversas de la psicología dominante al servicio del modelo neoliberal. Para ello se requiere la construcción de autonomía y reflexionar si lo que hacemos como psicólogas o psicólogos es en función de adaptar o subvertir.

Barrero propone cinco tesis sobre la formación de psicólogas y psicólogos. Sus reflexiones son el resultado de veinte años de trabajo en Colombia por la descolonización de la psicología desde la organización autónoma de psicología social "Cátedra Libre Martín-Baró" y de múltiples diálogos y acciones conjuntas con colegas de América Latina reflejados en tres movimientos de integración de la psicología 1) Unión Latinoamericana de Entidades de Psicología Ulapsi 2) Asociación Latinoamericana para la Formación y la Enseñanza de la Psicología Alfepsi y 3) el Movimiento Latinoamericano de Psicología de la Liberación.

Las cinco tesis a considerar en la formación de psicólogas y psicólogos en américa latina son:

1. Formar en Psicología para una estética de la existencia material, psicológica y espiritual de los pueblos en condiciones de dignidad. 
2. Una Psicología para el respeto irrestricto de las formas de existencia, costumbres y procesos psicosocio-antropológicos de nuestros pueblos.

3. Formar para la democratización del saber psicológico en contra de cualquier forma de despotismo, autoritarismo, imperialismo o colonialismo.

4. Una Psicología comprometida con la construcción de la autonomía y de la justicia cognitiva, afectiva, espiritual y relacional de los pueblos del mundo.

5. Formar en el espíritu colectivo de la investigación de alto nivel con fines de integración, unidad y fortalecimiento humanista de la Psicología en el continente latinoamericano.

El libro La psicología como engaño resalta la crisis de la psicología y aunque se refiere particularmente al contexto colombiano, la visión crítica de la teoría y práctica de la psicología es aplicable al contexto latinoamericano ya que las problemáticas son muy similares y la colonización intelectual está presente en los diferentes países de América Latina. El autor hace un llamado a la reflexión de la praxis psicológica en función de la ética e implicaciones políticas y de la congruencia con la trasformación de las problemáticas particulares de cada contexto.

\section{REFERENCIAS}

Ardila, R. (2013). Historia de la Psicología en Colombia. Bogotá: Editorial Manual Moderno.

Fals Borda, O. (2012). Casos de imitación intelectual colonialista. En N. Herrera y l. López (Comps.), Ciencia, compromiso y cambio social. (págs. 103-106). Buenos Aires: Editorial El Colectivo. Recuperado de https://www.extension.udelar.edu.uy/wp-content/uplo 
ads/2016/12/08 Ciencia_Compromiso_y_Cambio_So cial-Fals Borda.pdf

Martin-Baró, I. (1998). Psicología de la Liberación. Madrid: Editorial Trotta.

CÓMO CITAR ESTA RESEÑA

Villegas Ramírez, C. (2020). Reseña de Barrero (2017) La psicología como engaño ¿Adaptar o subvertir? Caleidoscopio Revista Semestral de Ciencias Sociales y Humanidades, 23(42), 325-333. doi:10.33064/4lcrscsh2189 